\title{
QUEEN'S
UNIVERSITY
BELFAST
}

\section{Phase Angle Difference Analysis Using PMU Data on grids with Varying Wind Penetration}

Duggan, C., Brogan, P., Liu, X., \& Morrow, J. (2021). Phase Angle Difference Analysis Using PMU Data on grids with Varying Wind Penetration. In 2021 56th International Universities Power Engineering Conference:

Proceedings: Powering Net Zero Emissions, UPEC 2021 - Proceedings (2021 56th International Universities Power Engineering Conference: Powering Net Zero Emissions, UPEC 2021 - Proceedings). Institute of Electrical and Electronics Engineers Inc.. https://doi.org/10.1109/UPEC50034.2021.9548155

Published in:

2021 56th International Universities Power Engineering Conference: Proceedings

Document Version:

Peer reviewed version

Queen's University Belfast - Research Portal:

Link to publication record in Queen's University Belfast Research Portal

\section{Publisher rights}

(C) 2021 IEEE.

This work is made available online in accordance with the publisher's policies. Please refer to any applicable terms of use of the publisher.

General rights

Copyright for the publications made accessible via the Queen's University Belfast Research Portal is retained by the author(s) and / or other copyright owners and it is a condition of accessing these publications that users recognise and abide by the legal requirements associated with these rights.

Take down policy

The Research Portal is Queen's institutional repository that provides access to Queen's research output. Every effort has been made to ensure that content in the Research Portal does not infringe any person's rights, or applicable UK laws. If you discover content in the Research Portal that you believe breaches copyright or violates any law, please contact openaccess@qub.ac.uk. 


\title{
Phase Angle Difference Analysis Using PMU Data on grids with Varying Wind Penetration
}

\author{
Connor Duggan, Paul Brogan, Xueqin Liu, John Morrow \\ School of Electronics, Electrical Engineering and Computer Science \\ Queen's University Belfast \\ United Kingdom
}

\begin{abstract}
Phase angle differences on a power system are strongly correlated to active power transfer and system topology. The transition from centralized thermal generation to distributed generation is driving phase angle variation in unprecedented ways. In this study, PMU data from three sites across Ireland are studied along with other power system metrics, including system demand and wind generation. Linear regression is used to analyse phase angle variation from power system metrics; the results are used to identify system operating parameters and predict future operating conditions as Ireland's wind resource expands. It is demonstrated that anticipated wind expansion may cause phase angle variation across the network that exceeds operational thresholds. The methods of wrangling and joining different power system data sources and the sequential forward selection regression function can be applied to the vast amounts of time series data generated from power system operation.
\end{abstract}

Index Terms-PMU, Linear Regression, Sequential Forward Selection, Phase Angle Difference, PSM

\section{INTRODUCTION (HEADING 1)}

In Ireland, a target has been set for $40 \%$ of electrical generation to be from renewable sources by 2020 [1]. This transition has transformed Ireland's energy supply from a bulk, centralized and well-controlled generation to distributed and weather dependent generation. Ireland has an abundant wind resource, which has become the primary source of renewable generation.

Operating the power grid at increased wind penetration levels leads to many concerns, including low inertial and voltage issues [2] and large phase angle differences [3]. Due to vulnerability playing an increasing role in how electricity is generated and consumed, this has resulted in power system stability becoming a significant factor for utilities to manage and innovate [3] effectively.

An additional power system stability concern involves phase angle variation across the power system. EirGrid/SONI (Ireland's TSOs) have identified this security vulnerability and have set an Operating System Standard limit of 40 degrees across transmission lines [4]. With significant levels of wind generation from the west of Ireland, this will increase the MW flow across transmission lines. However, wind generation has a finite contribution to inertia, which will influence post-fault stability. This research shows the variation in phase angle across the power system as wind output varies.

The data sets used covers the calendar year of 2017. Two different types of the dataset were joined for this investigation; they were PMU data and publicly available power flow data provided by EirGrid/SONI [5].

Developments in smart grid technology have seen PMU deployment rapidly increase on transmission systems. PMU provides high-resolution frequency, RoCoF and voltage, and current measurements for real-time and offline analysis. PMUs are usually connected to sites of mass thermal generation and at points in the power grid where there are significant substation and HVDC connections. Growing numbers of renewable generation sites are now being monitored by PMUs [6]. A primary driver of PMU deployment is the potential for increased stability and intelligent control of transmission and distribution networks.

The phase angle difference between vectorized angle measurements from PMU can be used as a proxy for active power flow from one part of a power system to another. Large phase angle differences result from large power flows and impedances between areas. An increased phase angle can be a vital diagnostic tool for system weakening and the potential onset of oscillations [7]. Incidents such as [7] have introduced phase angle limits on many major networks.

This paper assesses the effect of wind generation on phase angle difference using three PMUs based in Donegal, Belfast and Dublin. Using sequential forward selection (SFS) linear regression, this study analyses the phase angle across the network depending on multiple power system metrics (PSM). This research contributes to assessing wind generation of the volatility of angle constraints across a transmission network.

\section{BACKGROUND}

\section{A. Ireland's Transmission System}

Ireland's transmission network is a two-area system, consisting of Northern Ireland (NI) and the Republic of Ireland (RoI). NI's transmission system contains high voltage transmission lines of $275 \mathrm{kV}$ and $110 \mathrm{kV}$ and is operated by SONI (System Operator Northern Ireland). While the RoI is operated at $400 \mathrm{kV}, 220 \mathrm{kV}$ and $110 \mathrm{kV}$ and is operated by EirGrid. The two systems are synchronized via tie lines between Strabane/Letterkenny, Enniskillen/Corraclassy and Tandragee/Louth. The systems also import and export via two undersea HVDC cables connected to Great Britain.

Ireland has $1 \mathrm{GW}$ of HVDC interconnections, split between the Moyle interconnector near Belfast and the EWIC interconnector near Dublin. The all-island system would be considered small, with an average demand of $\sim 3.5$ GW and a maximum demand of $\sim 7$ GW. In 2017 Ireland had $\sim 3 \mathrm{GW}$ of installed wind capacity, expected to increase 

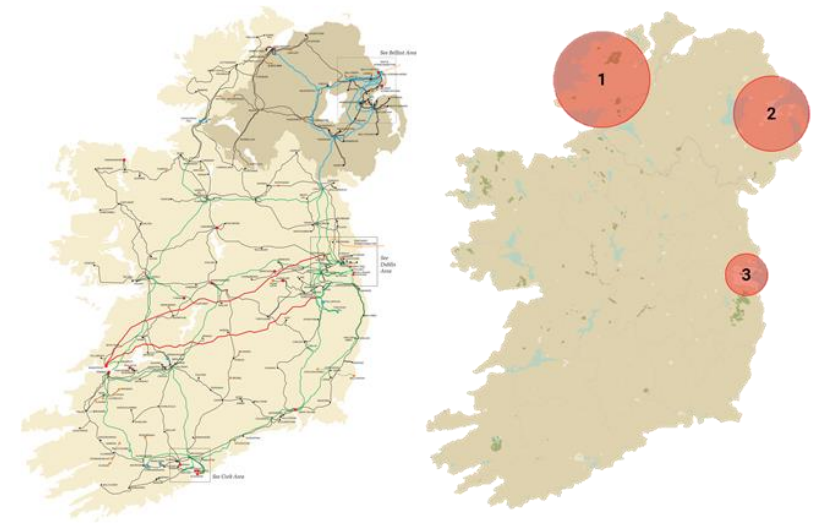

Fig 1. Irelands transmission system [7] (left); PMU placement map

to $\sim 4.5 \mathrm{GW}$ by 2023 [8]. The significant level of nonsynchronous penetration makes the Irish system useful for anticipating conditions on larger systems as they increase their renewable penetration. Ireland's transmission system and the locations of the PMUs are shown in Fig. 1.

\section{B. Transmission Line Theory}

The transmission line model in Fig. 2 allows a prediction of expected trends in PMU data with changes in PSM data. In this scenario the supplying voltage in Dublin can be considered as $V_{S}$ and that in Donegal as $V_{R}$, here capacitance is neglected as it is expected to be small in comparison with inductance. The conditions that vary are system demand $Z_{R}$ and wind power generation. Experimentally it has been observed that the phase angle variation between these two locations does not exceed $25^{\circ}$.

\section{1) Condition 1-Negative Phase Angle}

This represents conventional power flow, where central power stations supply loads at the peripheries. During these conditions, $I_{1}$ is positive as $I_{3}>I_{2}$ as wind power generation is less than local demand. The phase angle $\theta$ is expected to be negative as the power flow is expected to be from $V_{S}$ to $V_{R}$, as presented in Fig. 3.

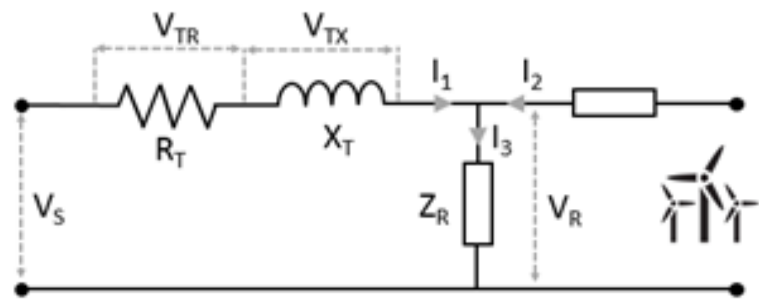

Fig. 2 Short length transmission line model

\section{2) Condition 2 - Positive Phase Angle}

Condition 2 occurs when distributed generation exceeds the local system demand. In this circumstance $\mathrm{I} 2>\mathrm{I} 3$ and $\mathrm{I}_{1}$ become negative. This results in a positive phase angle as power is supplied from the peripheries to a centralized load. This condition is presented in Fig. 3. This circumstance could result in high supply voltages however, this is mitigated with on-load tap changing transformers.

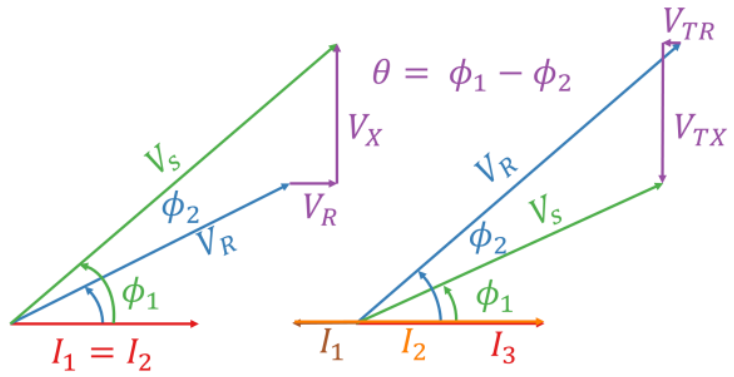

Fig 3. Condition 1, negative phase angle (left) and Condition 2, poistive phase angle (right), between distributed generation and load center

\section{Machine Learning Techniques}

This analysis is compiled of PMU data and PSM data from the transmission systems in NI and the RoI. The proposed methodology is proven useful to identify the "macros", baselining and typical angle differences across the transmission system. This paper also highlights the benefit of amalgamating different utility data sources to further transmission system research. Different system conditions are classified using high-resolution PMU vector measurements and machine learning techniques.

\section{1) Using PMUs for Phase Angle Monitoring}

Phasors reduce a sinusoidal waveform to a complex number. The signal mathematically represented in Eq. (1):

$$
x(t)=X_{m} \cos (\omega t+\phi)
$$

where $\omega$ if the angular frequency, $\emptyset$ is the phase angle and $X_{m}$ is the peak amplitude. To measure phase angle between two separate phase measurements they must have been sampled at the same time stamp. It can be said that two sinusoidal voltage signals (shown in Fig. 4) have a phase difference equal to $\left(\phi_{2}-\phi_{1}\right)$. Since both signals are tagged at a common reference point in time, in each angle study a single synchrophasor is chosen as the reference.

\section{2) Multiple Linear Regression}

Linear regression is a statistical approach that models the linear relationship between a scalar dependent variable $y$ and one or more explanatory variables. Multiple regression will model one or more explanatory variables $x_{N}$ to fit a linear model predicting $y$, as in (2).

$$
y=\beta_{0}+\beta_{1} x_{1}+\beta_{2} x_{2}+\cdots \beta_{k} x_{k}+\varepsilon
$$
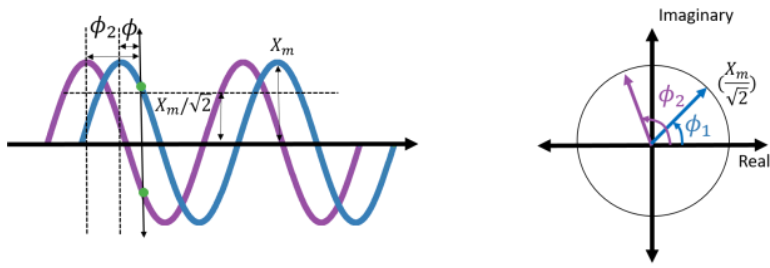

Fig 4. Phasor representation of two sinusoidal signals 
The $\beta$ values represent the regression coefficients, with $B_{0}$ representing the intercept and $\varepsilon$ representing the error. Once a model is trained using multiple explanatory variables and dependent variables, the regression model can be used to predict $y$ values. The use of the model is often limited by the training set used.

3) Sequential Forward Selection (SFS)

The main goal of SFS is to choose features from the extracted feature that give the best model scoring. SFS is a bottom-up search procedure which starts from an empty feature set iteratively adds features; selected by the scoring metric shown in Algorithm 1 [9]. The SFS algorithm takes a $d$-dimensional features as input and returns a subset of features $k$. Then the algorithm is initialized with an empty set $\emptyset$ so that $\mathrm{k}=0$. In line 1 , an additional feature is added, $y^{+}$to the feature set $Y_{k}$

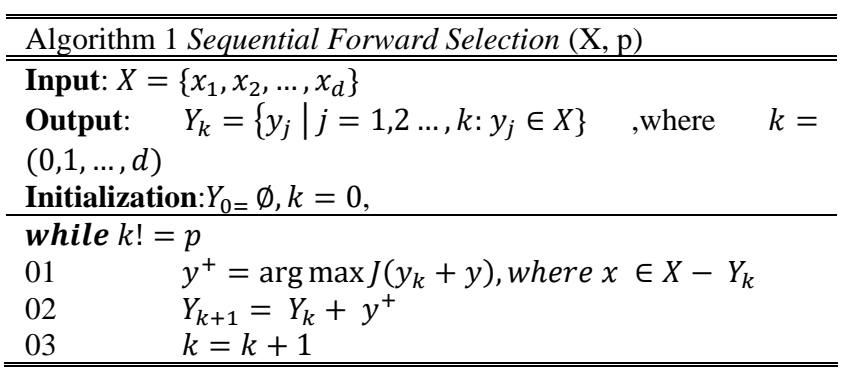

The feature that is added is the feature which gives the linear classifier the best score is added to $Y_{k}$. Features are added to the subset $Y_{k}$ until the feature subset of size $k$ contains the predetermined number of features $p$. SFS is a popular technique for reducing the dimensionality of a feature subset to find quickly which variables iteratively give the best prediction.

\section{EXPIERMENTAL PROCEDURE}

\section{A. Description of Data Sets Used}

The datasets used in this study have been compiled from various data sources during the year 2017. They consist of PSM data publicly available from SONI and EirGrid and data measured by PMUs across the Irish network. The datasets comprise of HVDC interconnector MW flow (Moyle \& EWIC), wind generation (NI and RoI), system demand, system generation and PMU measurements from the three locations displayed in Fig. 2. Table 1 outlines the data collected and the regions covered. These variables are used to analyse their influence on the phase angle across the transmission network.

\section{B. Cleaning \& Joining Dataset}

The datasets have been cleaned and joined using the Python library Pandas [10]. The workflow is presented in Fig. 5, displaying the steps taken to concatenate, join and clean data from a variety of sources. The "asof merge" was used to join data frames based on their timestamp. No cleaning of the PSM data was required, but when null values were encountered the whole row of data was removed. However, variables in the PSM metric dataset were highly correlated. This added multicollinearity into the regression model occurs when multiple features are correlated to response variable and each other. This will result in some of the regression equations becoming skewed. As a result, regional wind from ROI and NI is removed for the regression analysis for PSM metric data.

The frequency differential for each PMU was calculated. If any absolute differential value was above $0.001 \mathrm{~Hz}$, the row of data is removed as this indicated that the PMU was offline or desynchronized from the main system or GPS. Finally, data was removed if an absolute phase angle difference of greater than $35^{\circ}$ was observed between PMUs, this also indicated that a PMU was offline or desynchronized.

\section{TABLE 1: DESCRIPTION OF DATASETS}

\begin{tabular}{|c|c|c|c|}
\hline Data Type & Location & Abbreviation & Units \\
\hline \multicolumn{4}{|c|}{ EirGrid PSM Data } \\
\hline $\begin{array}{l}\text { System } \\
\text { Demand }\end{array}$ & ALL, ROI, NI & $\begin{array}{l}\text { SD_ALL, SD_ROI, } \\
\text { SD NI }\end{array}$ & MW \\
\hline $\begin{array}{l}\text { Wind } \\
\text { Generation }\end{array}$ & ALL, ROI, NI & $\begin{array}{l}\text { WG_ALL, } \\
\text { WG_ROI, WG_NI }\end{array}$ & MW \\
\hline $\begin{array}{l}\text { System } \\
\text { Generation }\end{array}$ & ALL, ROI, NI & $\begin{array}{l}\text { GEN_ALL, } \\
\text { GEN_ROI, } \\
\text { GEN_NI }\end{array}$ & MW \\
\hline \multicolumn{4}{|l|}{ Interconnector } \\
\hline NET & ALL & NET & MW \\
\hline Moyle & NI & MOY & MW \\
\hline EWIC & ROI & EWIC & MW \\
\hline \multicolumn{4}{|l|}{ SONI Data } \\
\hline $\begin{array}{l}\text { Tandragee- } \\
\text { Louth Tie Line }\end{array}$ & ALL & TL_I & MW \\
\hline \multicolumn{4}{|l|}{ PMU Data } \\
\hline Frequency & $\begin{array}{l}\text { Belfast, Donegal, } \\
\text { Dublin }\end{array}$ & N/A & $\mathrm{Hz}$ \\
\hline$V_{a}$ Angle & $\begin{array}{l}\text { Belfast, Donegal, } \\
\text { Dublin }\end{array}$ & N/A & $\circ$ \\
\hline
\end{tabular}

\section{Phase Angle Regression Analysis}

The relationship between the phase angle difference (between Donegal, Belfast and Dublin) and multiple power system metrics was investigated using regression analysis. The SFS algorithm, from mlxtend [9] was used to extract the features that gave the highest residual squared score. The first operation performs linear regression on the entire dataset. In the second operation, the derived wind penetration is added as an attribute and phase angle regression is carried out.

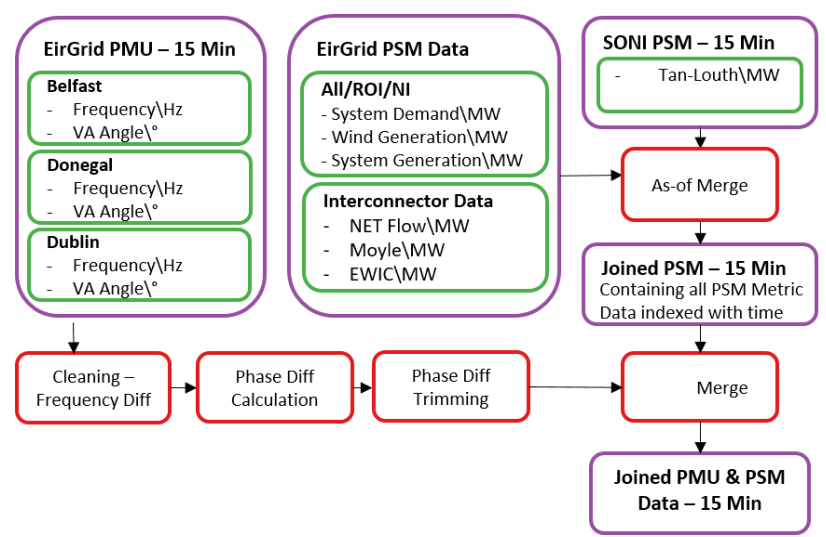

Fig 5. Phase angle estimation methodology 
It is important to consider which data to include in the explanatory dataset as correlations can exist within the dataset. As an example, regional and total wind can have similar predictive values as they are often proportional. This can easily be tested by carrying out a regression analysis on the columns within the explanatory dataset. Ideally columns with low mutual correlation are chosen as explanatory variables. In this investigation, wind generation and system demand are very poorly correlated but are often selected. A common metric of wind input is wind penetration, this is derived from wind generation divided by demand. Wind penetration is therefore a derived value. Wind penetration was investigated separately and found to be a slightly better predictor than wind generation or system demand, but not better than a combination. As Irelands wind generation increases, consideration of the magnitudes of wind and demand may be necessary, rather than the ratio of the two.

\section{RESULTS}

A criticism of some machine learning techniques is that they may not provide insight into the problem while they may perform reliably. In this investigation, the chosen explanatory variables are well understood in combination with the physical principles, and their coefficients can be interpreted. This provides insight into the operation of the power system and allows for the prediction of future conditions.

In this investigation, the residual squared value $\mathrm{R}^{2}$ is taken to measure the explanatory ability of the explanatory variables. It is considered important also visually to inspect the regression data to look for outliers. Fig. 6 illustrates the agreement between the predicted values (based on the regression analysis) and the measured values. If perfect agreement existed, then the values would form a straight line, with a greater width indicating less agreement. The line of best fit indicates the general trend, ideally a gradient of one and an intercept of zero to be found. Plots such as Fig. 6 indicates if a higher-order polynomial regression is required to explain the observed values.

The full regression results are displayed in Table 2, 3 and 4. The optimal features, or explanatory variables, are presented in the top line, with the intercept and gradients

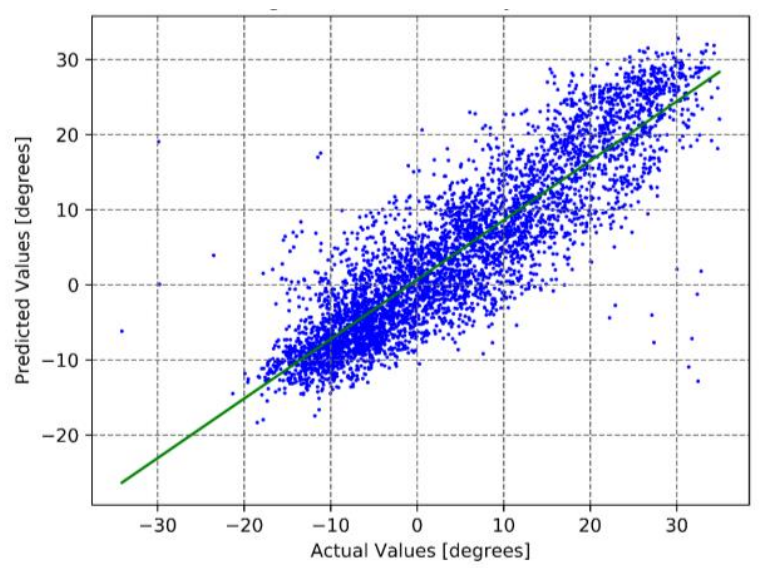

Fig 6. Donegal-Dublin phase angle difference of predicted (green straight line) and measured values (blue dots)
TABLE 2. SFS REGRESSION DONEGAL-DUBLIN PHASE DIFFERNCE

\begin{tabular}{l|c|l|l|c|c|c}
\hline \hline DD1 & \multicolumn{1}{c}{$\boldsymbol{R}^{\mathbf{2}}$} & \multicolumn{1}{c}{$\boldsymbol{\beta}_{\mathbf{0}}$} & \multicolumn{1}{c}{$\boldsymbol{\beta}_{\mathbf{1}} \boldsymbol{x}$} & \multicolumn{1}{c}{$\boldsymbol{\beta}_{\mathbf{2}} \boldsymbol{x}$} & \multicolumn{1}{c}{$\boldsymbol{\beta}_{\mathbf{3}} \boldsymbol{x}$} & $\boldsymbol{\beta}_{\mathbf{4}} \boldsymbol{x}$ \\
\hline FEATURES & \multicolumn{2}{l|}{} & WG_ALL & SD_ALL & TL_I & GEN_NI \\
\hline Model 1 & 0.72 & -10.3 & 0.014 & - & - & - \\
\hline Model 2 & 0.77 & 3.9 & 0.014 & -0.004 & - & - \\
\hline Model 3 & 0.79 & 4.78 & 0.014 & -0.004 & -0.014 & - \\
\hline Model 4 & 0.80 & 7.21 & 0.014 & -0.006 & -0.015 & 0.007 \\
\hline \hline
\end{tabular}

TABLE 3. SFS REGRESSION DONEGAL-BELFAST PHASE DIFFERENCE

\begin{tabular}{l|c|c|l|c|c|c}
\hline \hline DB1 & \multicolumn{1}{c}{$\boldsymbol{R}^{\mathbf{2}}$} & \multicolumn{1}{c}{$\boldsymbol{\beta}_{\mathbf{0}}$} & \multicolumn{1}{c}{$\boldsymbol{\beta}_{\mathbf{1}} \boldsymbol{x}$} & $\boldsymbol{\beta}_{\mathbf{2}} \boldsymbol{x}$ & \multicolumn{1}{c}{$\boldsymbol{\beta}_{\mathbf{3}} \boldsymbol{x}$} & $\boldsymbol{\beta}_{\mathbf{4}} \boldsymbol{x}$ \\
\hline FEATURES & & WG_ALL & MOY & SD_ROI & GEN_NI \\
\hline Model 1 & 0.64 & -8.99 & 0.012 & - & - & - \\
\hline Model 2 & 0.73 & -8.72 & 0.012 & -0.016 & - & - \\
\hline Model 3 & 0.75 & 1.09 & 0.013 & -0.009 & -0.003 & - \\
\hline Model 4 & 0.75 & 2.73 & 0.012 & -0.011 & -0.006 & 0.008 \\
\hline \hline
\end{tabular}

TABLE 4. SFS RERGESSION DUBLIN-BELFAST PHASE DIFFERENCE

\begin{tabular}{l|c|cc|c|c|c|c}
\hline \hline DB1 & \multicolumn{2}{c}{$\boldsymbol{R}^{\mathbf{2}}$} & $\boldsymbol{\beta}_{\mathbf{0}}$ & \multicolumn{1}{c}{$\boldsymbol{\beta}_{\mathbf{1}} \boldsymbol{x}$} & \multicolumn{1}{c}{$\boldsymbol{\beta}_{\mathbf{2}} \boldsymbol{x}$} & \multicolumn{1}{c}{$\boldsymbol{\beta}_{\mathbf{3}} \boldsymbol{x}$} & $\boldsymbol{\beta}_{\mathbf{4}} \boldsymbol{x}$ \\
\hline FEATURES & \multicolumn{2}{l|}{} & TL_I & WG_ALL & MOY & GEN_NI \\
\hline Model 1 & 0.60 & 0.48 & 0.023 & - & - & - \\
\hline Model 2 & 0.67 & 1.70 & 0.023 & -0.001 & - & - \\
\hline Model 3 & 0.69 & 1.67 & 0.021 & -0.001 & -0.003 & - \\
\hline Model 4 & 0.74 & -2.03 & 0.019 & -0.002 & -0.008 & 0.005 \\
\hline \hline
\end{tabular}

beneath. Single order regression was carried out as it is easier to interpret and is more robust for basic extrapolation.

\section{A. Phase Angle Variation Between Dublin and Donegal}

Displayed in Table 2 are the results of estimating the phase angle difference between Dublin and Donegal. Both locations are on the RoI network. It can be noted that the first explanatory value chosen was total wind generation.

Model 1 in Table 2 has an intercept of -10.3, this indicates that the average phase angle difference, at zero wind generation, is $-10.3^{\circ}$. The gradient of the wind generation (WG_ALL) explanatory value is +0.014 per MW, this indicates that for every $\mathrm{GW}$ rise in wind generation an angle shift of $14^{\circ}$ degrees occurs. The fact that the gradient of the variable does not change, as further explanatory variables are added, suggests this conclusion is reliable.

In 2017 the wind capacity of Ireland was approximately $3 \mathrm{GW}$, therefore a maximum angle variation of $31.8^{\circ}$ might be expected; this agrees with Fig. 6. Suppose wind turbines continue to be installed in similar regions and at similar voltage levels. In that case, a phase angle difference of $52.7^{\circ}$ might be expected at a wind generation of $4.5 \mathrm{GW}$, expected in 2023. This degree of phase angle variation would exceed operating parameters [4].

The next explanatory variable chosen in Model 2, Table 2, is the all-Ireland system demand. It can be noted that, for every increase of $1 \mathrm{GW}$ of load, a phase angle shift of $-4^{\circ}$ can be expected. This demonstrates how system load can offset high phase angle variations. In this case, interpreting the intercept has less value, but it indicates that a phase angle of $+3.9^{\circ}$ would exist if there was no wind 
generation or load on the system; this likely relates to line capacitance.

The next two explanatory variables chosen are the tie lines between the two systems and wind generation in NI. The tie lines refine the angle estimate and are a useful explanatory variable as is has little correlation with wind generation or system demand. Finally, wind generation in NI is highly correlated with total wind generation; the variable is chosen as it helps refine the angle estimate as the wind in NI correlates highly with local wind generation, given the geographic location.

\section{B. Phase Angle Difference between Donegal \& Belfast}

Table 3 shows the regression analysis of the angle difference between Donegal and Belfast. The angle variation shows the strongest correlation with total wind generation. In this case the angle variation is smaller, $-12^{\circ}$ per GW. In the absence of wind generation, an average phase angle of $-8.99^{\circ}$ can be inferred from the intercept.

The second explanatory variable shows a strong correlation with the Moyle HVDC interconnector. This interconnector has a capacity of $\pm 500 \mathrm{MW}$, indicating the angle would vary by $\pm 8^{\circ}$. This correlation should be treated with a degree of skepticism, as the HVDC interconnectors are a controlled asset and often export when wind power is high and import when wind power is low.

The further explanatory variables can be understood as an increase in system demand in the RoI makes the angle difference between Donegal and Belfast more negative, while generation in NI makes the angle more positive. In this case, analysis is complicated as we also need to consider two synchronous systems, but the understanding can be reduced to transmission line theory.

\section{Phase Angle Difference between Dublin and Belfast}

Table 4 shows the regression analysis on the angle variation between Dublin and Belfast. These two cities are the major load centers on their power systems. The explanatory variable that agrees most strongly with the angle variation is tie line flow. To some extent this is a prosaic observation as power flow between these regions is driven by angle difference between these synchronous systems.

Once tie line flow is accounted for, the regression technique can identify the other predictors of phase angle. It can be noted that an increase in wind power makes the phase angle more negative, indicating power export to NI. A similar conclusion could be drawn from the Moyle interconnector; however, this may be correlation rather than causation, as power import from the RoI may be more desirable than HVDC import at times of high demand.

\section{CONCLUSIONS AND FUTURE WORK}

In this paper, a methodology for phase angle prediction has been assessed by combining PMU and PSM data. A simple first order polynomial regression was found to provide high degrees of correlation. The method of combining and analyzing datasets has been discussed and is widely applicable to general research on power systems.
In this study the phase angle difference between a remote wind generation region and load centers was found to be primarily driven by wind generation, followed by system demand. The coefficients of the regression analysis can be easily interpreted, as the estimation parameters are well understood. The results of this study strongly indicate that phase angle increases by $14^{\circ}$ for every GW of wind generation. In 2017 Ireland had a wind capacity of $\sim 3 \mathrm{GW}$, explaining the observed phase angle difference of $31.8^{\circ}$. Ireland plans to increase wind generation to $\sim 4.5 \mathrm{GW}$ by 2023, which could potentially result in a phase angle variation of $52.7^{\circ}$; this exceeds the maximum operating condition of $40^{\circ}$ on the transmission system [4].

Regression analysis for estimating phase angle allows for tests against defined system conditions, which may cause "sources" and "sinks" in the power system. Although linear models are limited by the fact they are based on historical data, the model allows for estimation of voltage phase angle for both historically and near time operations. This research is part of an existing project investigating phase angle differences across the Irish power system for defining interarea and voltage stability limits. Regression analysis for voltage angle difference and MW flows provides a deeper understanding of the dynamics of an interconnected power system with high wind penetration.

\section{ACKNOWLEDGEMENTS}

The authors will like to acknowledge the financial support from SPIRE2 project (Storage Platform for the integration of Renewable Energy) and data from Eirgrid/SONI. The SPIRE 2 project is supported by the European Union's INTERREG VA Programme, managed by the Special EU Programmes Body (SEUPB). The views and opinions expressed in this paper do not necessarily reflect those of SEUPB.

\section{REFERENCES}

[1] M. Holland and M. Howley, "Renewable Electricity in Ireland $2015, " 2016$.

[2] A. Ulbig, T. S. Borsche, and G. Andersson, "Impact of low rotational inertia on power system stability and operation," IFAC Proc. Vol., vol. 19, pp. 7290-7297, 2014, doi: 10.3182/20140824-6-ZA-1003.02615

[3] A. J. Allen, S. Santoso, and W. M. Grady, "Voltage phase angle variation in relation to wind power," IEEE PES Gen. Meet. PES 2010, pp. 1-7, 2010, doi: 10.1109/PES.2010.5590001.

[4] Eirgrid, "Operating Security Standards," 2010. http://www.eirgridgroup.com/sitefiles/library/EirGrid/Operating-Security-Standards-December2011.pdf (accessed Nov. 28, 2018).

[5] Eirgrid Group, "EirGrid Group plc - Smart Grid Dashboard." http://smartgriddashboard.eirgrid.com/ (accessed Dec. 04, 2018).

[6] A. Rajeev, R. Shanmugarajeshwaran, T. Poonurangam, and E. Sreevalsan, "Applications of PMU in renewable energy generation," 2016 3rd Int. Conf. Electr. Energy Syst. ICEES 2016, pp. 294-297, 2016, doi: 10.1109/ICEES.2016.7510656.

[7] K. E. Martin, "Phasor measurement systems in the WECC," 2006 IEEE PES Power Syst. Conf. Expo. PSCE 2006 - Proc., pp. 132-138, 2006, doi: 10.1109/PSCE.2006.296287.

[8] Eirgrid, "All-Island Generation Capacity Statement 2017-2026," 2017. http://www.eirgridgroup.com/site-

files/library/EirGrid/4289_EirGrid_GenCapStatement_v9_web. pdf (accessed Dec. 07, 2018).

[9] S. Raschka, "MLxtend: Providing machine learning and data science utilities and extensions to Python's scientific computing 
stack," J. Open Source Softw., vol. 3, no. 24, p. 638, 2018, doi: 10.21105/joss.00638.

[10] Wes McKinney, "Data Structures for Statistical Computing in Python," PROC. 9th PYTHON Sci. CONF. (SCIPY, vol. 19, no. 5, pp. 583-591, 2010, doi: 10.1002/mmce.20381. 